\title{
Work in Team - Improve your GIS Skills Effectiveness of project work in teaching GIS for foreign students
}

\author{
Krisztina Irás ${ }^{a}$ *, José Jesús Reyes Nuñez ${ }^{b}$ \\ ${ }^{a}$ ELTE Ë̈tvös Loránd University, Department of Cartography and Geoinformatics, iras@map.elte.hu \\ ${ }^{b}$ ELTE Eötvös Loránd University, Department of Cartography and Geoinformatics, jesusreyes@ caesar.elte.hu \\ * Corresponding author
}

Keywords: Teaching GIS, Field work, Environmental mapping, International students, Thematic maps

\begin{abstract}
:
In 2013, the Hungarian Government opened a scholarship programme called Stipendium Hungaricum for foreign students to study in the Hungarian higher education. Within this scholarship, students coming from non-European Union countries complete full studies at both bachelor and master levels in Hungarian universities. Three years ago, the first international students financed by Stipendium Hungaricum arrived to the Department of Cartography and Geoinformatics of ELTE Eötvös Loránd University to study cartography and geoinformatics at master level. Since then the success of the programme constantly encourages students to choose our degree program.
\end{abstract}

Teaching GIS for "beginners", i.e. for those who finished their studies in other areas and are new in our field, is not easy for its multidisciplinary nature. Teaching Z generation might be a challenge for modern issues of generation gap. Teaching international students from very different countries is also not easy because of very different professional backgrounds and exercises, studying habits and language skills, in some cases. Teaching GIS for foreign students is a combination of these aspects and led us to develop new methodological and pedagogical approaches in order to reach success both for students and professors.

On this poster, we present one of our solutions: the "Geoinformatic and Cartographic Project" work. It is a large, complex practical subject for second year students, which needs all the previous studies of the first year and much of individual work and creativity. Students work driven by professors, but mostly individually. The topic is mapping environmental conditions of Vác, a charming small town at the bank of the Danube, $20 \mathrm{~km}$ to the North from Budapest.

Students work in pairs. This is comfortable for sharing the tasks not only in the field work but in the lab work too, while they can also show their individual skills. For completing the task they need to do some theoretical research and they have to get familiar with the tools (noise meter, thermometer, solar radiation device, GPS) and specific software (ArcGIS, Qgis; Global Mapper; graphic software eg. OCAD, Corel Draw; Open Layers, etc.). They have to cope with real life situations during data collecting and have to learn timing their work. The semester ends with an oral presentation of the results with data analysis.

The project has five phases: Phase 1: Preparation; Phase 2: Research; Phase 3: Field work; Phase 4: Lab work; Phase 5: Analysis and documentation

Results of the geoinformatic work are a complex environmental database with data on temperature, humidity, solar radiation and noise pollution; a series of thematic maps created from the collected data; and an interactive web site where users can consult the thematic maps and read the analysis of the data.

For the cartographic part of the project, students also prepare a hard copy touristic map of the town. This task needs touristic data collecting (including research, taking notes and pictures in the field work). The result is an independently edited and designed touristic map in the style of a city map.

In the poster, we would like to present the step-by-step workflow of the Geoinformatic and Cartographic Project (the phases in detail) with the resulting geodatabases, thematic maps and websites. We believe these are the steps that bring the students to the same level of GI knowledge, that facilitate them to work together in a team, and encourages them to lead sub-tasks, opens their imagination and to figure out their own ideas. A project work like this provides professional experience, strengthens problem-solving skills and gives self-confidence for the future GIS experts. 